\title{
Importance of Task Complexity
}

\author{
Ma'soumeh Sanayee (Corresponding author) \& Amir Rezaei \\ MA student, Islamic Azad University, Science and Research Branch, Zanjan, Iran \\ E-mail: msanayeiee@yahoo.com
}

Received: November 7, 2014 Accepted: November 27, 2014 Published: November 28, 2014

doi:10.5296/ijele.v3i1.6700 URL: http://dx.doi.org/10.5296/ijele.v3i1.6700

\begin{abstract}
Although the concept of task and its role has been a matter of much controversy in the field of second language acquisition (SLA), there is a general agreement that in language learning, task complexity is required for the effectiveness of the final performance of tasks, (Robinson, 2011).

This paper is an overview of the task based language teaching, task complexity, its definition and its importance in language education to gain more insights into this area and its effect on second language (L2) development. Robinson (2001, p. 29) defines task complexity as "the result of attentional, memory, reasoning, and other information processing demands imposed by the structure of the task on the language learner." Our goal is to gain further insights into this area of second language acquisition (SLA) research by understanding how task complexity works and the effects it has on L2 acquisition.
\end{abstract}

Keywords: Task Based Language Teaching, Task Complexity 


\section{Definition of Task Complexity}

In language learning, the influence of task complexity on the final performance of tasks is regarded important.

According to Robinson (2001b), "task complexity is the result of attentional, memory, and other information processing demands imposed by the structure of the task on the language learner "(p.29). Robinson believes that task complexity is based on the cognitive demands of each task in the phase of conceptualization. So complex concept will use more complex syntactic structures and these type of complicated tasks are more complex in respect of linguistic formation and conceptualization.

As stated by Robinson (2001) task complexity is related to the tasks cognitive dimensions and can be utilized in task design. So the complexity of the task will be effective on task performance.Task designers must make use of some operational framework for selectively adjusting and increasing the demands of tasks to gradually approximate real-world performance conditions.

In contrast, task difficulty concerns learners' perceptions of the demands of the task, and is dependent on differences between learners in the cognitive factors (e.g., aptitude, working memory) and affective variables (e.g., anxiety, confidence) that distinguish them from one another (see Robinson, 2001b; Spilsbury, Stankov, \& Roberts, 1990).

Thirdly, task conditions concerns the interactive demands of task performance, such as participant factors, whether the task participants are previously familiar with each other, or not, or the same versus different gender.

\section{Importance of Task- Based language Teaching (TBLT)}

Experimental research about task-based learning has been furthered by the suggested proposals for task based language teaching, Robinson (2011). It is stated by the cognition hypothesis that in task based language learning, pedagogical tasks are organized in a way to increase the complexity of cognition. Thus it will lead to the fulfillment of real world target tasks demands (Robinson 2003). Three issues are predicted by cognition hypothesis as the result of increasing the cognitive demands. Thus based on this hypothesis learners will be pushed to achieve to a higher level of accuracy and complexity in L2 production that will result in greater level of communication .Second, interaction and attention to input will be increased. Third, having individual differences in cognitive and affective features will cause differences in the performance of learning tasks and also the level of complexity will be increased.

Yuan and Ellis (2003) asserted that pre-task planning can directly have a positive influence on language production in terms of fluency and complexity. The results showed that grammatical complexity will be enhanced by pre -task planning while accuracy and grammatical complexity will be influenced by on-line planning. Furthermore pre-task learners will produce fluent language in comparison with online learners. So the condition of tasks are essential for the promotion of accuracy, complexity and fluency in monologic speech 
production.

The effects of planning in task based instruction have been investigated by Ellis (2005) and Foster and Skehan (1996). The findings of the study can reveal the importance of teacher training in the increase of task-based instruction in foreign language classrooms. Hence, teachers should have information about different types of planning strategies and also designing tasks to increase communicative tasks.

In the article which was presented by Tavakoli and Foster (2008), the effect of narrative structure and complexity on the performance of second language learners is examined.

In summary the results show that the level of complexity in stories is effective on syntactic complexity and grammatical accuracy can be promoted by structured narrative forms. The most important point is that learning condition and atmosphere does not have influential effect on the level of accuracy or fluency. But it is noteworthy that syntactic complexity and lexical diversity are affected by learning environment.

According to Wang (2008), Task-based language teaching (TBLT) is regarded as one of the most important methods in second language teaching. He wants to discuss the influence of Planning on the task performance of learners. He claims that although planning has significant influence on the performance of learners, there is not enough evidence to prove this fact.

Gurzynski-Weiss and Re've'sz,( 2012) proposed an approach to interactional feedback and tasks. The results showed that non-tasks were more effective in feedback provision and could provide opportunities in the production and communication of the language in comparison with the tasks. In conclusion the results of their study revealed that form-oriented activities like tasks in the laboratory can present a suitable pattern for promotion of interaction in language classrooms.

\section{Importance of Task Complexity}

The quality of the production has been affected by tasks and most of the research in task-based L2 research has been increased dramatically (e.g., Bygate, 1996, 2001; Robinson, 1995a; Skehan, 1998; Skehan \& Foster, 2001). The effects of task complexity on the syntactic complexity will lead to higher functional complexity in syntax (Bivon, 1985).Thus, increasing functional potentials will have a direct effect on L2 production (Givon, 1985, 1995, 2002).

According to R'evez (2011) participants demonstrated lower syntactic complexity but greater accuracy and lexical diversity when task complexity was increased. In particular, careful task manipulations may induce learners to engage in increased monitoring behavior, more extensive experimentation with the L2, and higher incidence of interaction-driven language learning opportunities.

Trebits (2012), proposed an approach to the relationship between different components and elements of lexical variety, fluency, and syntactic complexity in both written and spoken tasks. The gained results showed the support for Robinson's cognition hypothesis (2001b, 
2003, 2005b).The results of the mentioned study can provide and confirm the finding's of Robinson's (2001a,2005a) aptitude complex hypothesis.

O, Jackson and Suethanapornkul (2013), in their interpretive study focused on synthetic and meta-analytic techniques to review the literature on the cognition hypothesis (Robinson \& Gilabert, 2007. The results show that, small positive effects for accuracy and small negative effects for fluency were found. This lends support to the cognition hypothesis.

The study of Li,Chen, Liu, Cheng ( 2011), reveals that general objective measures are more related to task complexity in comparison with subjective measures .three objective measures that could predict task complexity were the following ones :1) the number of hard words ; 2) the number of required languages for searching results 3 ) and finally the number of task domain areas .

Rahimpour (2010), in his study on the effect of task complexity on written performance found that that task complexity has a strong effect on learner's fluency .As a result the findings of the study are in accordance with Skehan and Foster's Limited Attenational Capacity Models (Skehan, 1998; Skehan \& Foster, 1999, 2001).

The article of Kuiken and Vedder (2008) , confirm Robinson's Cognition Hypothesis and Skehan and Foster's Limited Attentional Capacity Model with respect to the written tasks and writing performance.

Robinson (1995) believes that, the more complex There-and-Then condition elicited greater accuracy and a higher ratio of lexical to grammatical words. There is also a trend suggesting greater utterance length for narratives performed under the simpler Here-and-Now condition. These results support the claim that complex tasks lead to less fluent, but more accurate and complex production than do simpler tasks.

Michel1, Kuiken2, and Vedder (2011), assert that a better understanding of how changes in the number of elements referred to in a task affect L2 production, and how this relates to cognitive task complexity. The aim was to increase our understanding of how manipulations of the factor ' \pm elements' and the factor ' \pm monologic', both on their own as well as in combination, influence oral L2 production. Results reveal hardly any effects of the manipulation of the number of elements.

Révész (2009), examined how task variables and contextual support along with focus on form technique influences L2 morpho-syntactic development. Results yield two main findings. First, learners who received recasts but did not view photos outperformed learners who received recasts while viewing photos. Second, the group that viewed photos but did not receive recasts achieved greater L2 gains than the group who neither viewed photos nor received recasts.

According to Heidari ,Dabaghi and Kassaian ( 2012), the effects of task complexity on the occurrence of LREs (Language related Episodes) are related on task types and learners proficiency. Their study only partially confirms Robinson's Cognition Hypothesis and Skehan's Model. 


\section{Conclusion}

In summary, Skehan assumes attentional capacity is generally available and limited, and that increase in task complexity drain attentional resources and are therefore likely to have the effect of degrading the fluency, accuracy, and complexity of output, as well as perception of input and intake (Doughty and Long (2003). In cases where complex tasks make demands that exceed the learners' available attentional resources, Skehan argues additional task structure is necessary to attract learner attention to relevant aspects of form, which would otherwise not be processed. A similar rationale underlies VanPatten's (1996) proposals for processing instruction. Increasing task complexity may also lead to greater retention of noticed input.

The alternative position makes the prediction that, increasingly complex interactive tasks result in greater amounts of negotiation (Robinson, 2001) they also increase learner chances for, and maybe therefore the likelihood of, making cognitive comparisons between input and output, leading to noticing "gaps" or holes in production (Doughty and Long (2003).These issues are speculative, unresolved, testable, of great practical relevance to second language pedagogy and curriculum design, and in much need of further SLA inquiry.

\section{References}

Andrea Révész, Sachs, \& Mackey. (2010). Task complexity, uptake of recasts, and L2 development. Lancaster University and Georgetown University

Doughty \& Long. (2003). The Handbook of Second Language Acquisition.

Kormos, J. (2012). The Role of Task Complexity, Modality, and Aptitude in Narrative Task $\begin{array}{llll}\text { Performance. Language Learning, } & \text { p. } & 134 .\end{array}$ http://dx.doi.org/10.1111/j.1467-9922.2012.00695.x

Nassaji, H. (2007). Elicitation and Reformulation and Their Relationship With Learner Repair in Dyadic Interaction. Language Learning, 57(4), 511.548.

Rahimpour, M., \& Hosseini, P. (2010). The Impact of Task Complexity on L2 LearnersWritten Narratives. English Language Teaching, 3(3), 198-205.

Re've' sz, A. (2012). Working Memory and the Observed Effectiveness of Recasts on Different L2 Outcome Measures. Language Learning, 62(1), pp. 93.132. http://dx.doi.org/10.1111/j.1467-9922.2011.00690.x

R'ev'esz, A. (n.d.). Task Complexity, Focus on L2 Constructions, and Individual Differences: A Classroom-Based Study.The Modern Language Journal (2011), 95, 162. http://dx.doi.org/10.1111/j.1540-4781.2011.01241.x

Robinson, P. (2003). The cognition Hypothesis, Task Design, and Adult Task-based Language Learning. Second Language Studies, 21(2), pp. 45-105.

Robinson, P. (2005). Cognitive complexity and task sequencing:Studies in a componential framework for second language task design. International Reviewof Applied Linguistics, 43, 
$1-32$.

Robinson, P. (1995). Task Complexity and Second Language Narrative Discourse. Language Learning, 45(1), 99.

Robinson, P. (2001). Task complexity, cognitive resources, and syllabus design: A triadic framework for investigating task influences on SLA. In P. Robinson (Ed.), Cognition and second language instruction. New York: Cambridge University Press, 287-318.

Robinson, P. (2001). Task complexity, task difficulty, and task production: exploring interactions. Applied Linguistics, 22(1), 27.

Robinson, P. (2007). Task complexity, theory of mind, and intentional reasoning: Effects on L2 speech production, interaction, uptake and perceptions of task difficulty. International Review of Applied Linguistics, 45, 193-213.

Robinson, P. (2011). Task-Based Language Learning: A Review of Issues. Language Learning, 61, 136.

Skehan, P., \& Foster, P. (1997). Task type and task processing conditions as influences on foreign language performance. Language Teaching Research, 1, 185-211.

Skehan, P. (2009). Modeling Second Language Performance: Integrating Complexity, Accuracy, Fluency, and Lexis. Applied Linguistics, 30(4), 510-532. http://dx.doi.org/10.1093/applin/am p047

Tavakoli, P. (2008). Task Design and Second Language Performance: The Effect of Narrative Type on Learner Output. Language Learning, 58(2), 439-473.

Yuan, F., \& Ellis, R. (2003). The effects of pre-task planning and on-line planning on fluency, complexity and accuracy in L2 oral production. Applied Linguistics, 24, 1-27.

\section{Copyright Disclaimer}

Copyright for this article is retained by the author(s), with first publication rights granted to the journal.

This is an open-access article distributed under the terms and conditions of the Creative Commons Attribution license (http://creativecommons.org/licenses/by/3.0/). 